\title{
Uncovering the scholarly use of Twitter in the academia: Experiences in a British University
}

\author{
Nordiana Ahmad Kharman Shah ${ }^{1}$ and Andrew M. Cox ${ }^{2}$ \\ ${ }^{1}$ Department of Library \& Information Science \\ Faculty of Computer Science and Information Technology \\ University of Malaya, 50603 Kuala Lumpur, MALAYSIA \\ ${ }^{2}$ Information School, The University of Sheffield \\ Regent Court Portobello, \\ Sheffield S1 4DP UNITED KINGDOM \\ E-mail:dina@um.edu.my (corresponding author); a.m.cox@sheffield.ac.uk
}

\begin{abstract}
The potential of social media such as Twitter has been seen as potentially transformational. However, most of these effects have been studied in the political, social or technological sphere. Its impact on scholarship remains under-researched. This paper explores how academics use Twitter as part of their scholarly activities. A qualitative approach based on an interpretative methodology was adopted for the study, and data gathered through 28 semi-structured interviews with academic staff who regularly use Twitter for academic and non-academic purposes. The findings uncover the rich benefits that enthusiasts gain from use of Twitter as an information source for scholarly communication - in the context of creation, usage and sharing of scholarly information. This was manifested in academics' information-seeking behaviour through links to networking and collaboration as part of scientific practice. Twitter's use as a micro-break is also described. The paper offers insights on how, despite these benefits, microblogging remains a minority activity.
\end{abstract}

Keywords: Scholarly communication; Information-seeking behavior; Microblogging; Twitter; Social media.

\section{INTRODUCTION}

In the last few years, much interest has been generated around social media use in Higher Education, as in other sectors. Indeed, some authors have argued that it may change the very nature of scholarly communication and identity (Kirkup 2010; Nicholas and Rowlands 2011; Veletsianos, Kimmons and French 2013; Veletsianos, 2013; Weller, 2011). For example, Weller's (2011) concept of digital scholarship envisages an academic who uses it to be "digital, networked and open" sharing thoughts on every aspect of scholarly activity with many audiences. Similarly, Veletsianos and Kimmons $(2012$, p.768) coin the term Networked Participatory Scholarship to describe scholars who use "participatory technologies" to "share, reflect upon, critique, improve, validate and further their scholarship." These concepts capture interesting possibilities, but research evaluating the impact of social media in a balanced way is somewhat lacking. 
Of social media platforms, Twitter is globally the second most popular, after Facebook (Wright et al. 2015). Similarly, in the academic context, a recent survey by Lupton (2014) found that Twitter was one of the most used forms of social media. Unlike Facebook it is a public network for professional activities, and not just for maintaining personal ties. Although messages are restricted to just 140 characters, Twitter can be used to share photos, videos and links, and users have been ingenious in how they have begun to make use of it in their practice.

A few empirical studies have been conducted to identify the benefits of microblogging for scholarly purposes. According to such research, some of the core uses of Twitter in the academic context are: as a channel to engage in professional and scientific conversations; as a backchannel to support communication at conferences; and as a means to enhance learning and teaching (Pearce et al. 2010; Pepe and Mayernik 2011; Veletsianos and Kimmons 2012; Veletsianos 2013). Twitter has also been found to be useful in connecting and maintaining networks among groups of practitioners and scholars and for developing professional learning networks (Alderton, Brunsell and Bariexca 2011; Dunlap and Lowenthal 2009; Greenhow and Robelia 2009; Trust et al. 2017).

Yet, in-depth, qualitative research of Twitter use in Higher Education for scholarly communication, particularly in the UK context is lacking. Many previous studies have either been broad surveys of social media use as a whole or small scale case studies, such as those investigating interesting pedagogic applications in a particular context. And despite the enthusiasm for social media like Twitter, actual take up of this platform in HE seems to be a minority activity. In this context, this paper explores how academics in a British university use Twitter as part of their scholarly activities.

The paper is set out as follows. It first reviews some of what we know from the literature about the impact on higher education of the use of social media and specifically Twitter. Then the interpretative, qualitative approach taken by the current study is outlined and data collection and analysis methods explained. The findings about academics' use of Twitter are then laid out, followed by a discussion of how it is used in scholarly communication. The conclusion explores the significance of the findings, its practical implications and proposes areas for further research.

\section{LITERATURE REVIEW}

The introduction of Web 2.0 technologies and social media has opened up new possibilities for academics in all aspects of their work. They are a means for educators to engage, communicate with and teach students in a new way (Selwyn 2012; Greenhow and Gleason 2014). They are also considered to be a tool for professional development (Selwyn 2007). Social media has also become widely used in higher education for marketing, public relations and reputation management (Reuben 2008; Foroughi 2011; Lupton 2014). Most fundamentally, Lupton (2014) has argued that these technologies also seem to have the potential to refashion scholarly communication by creating new forms of connection and new conversations. This was also observed by Gu and Widen-Wulff (2010) in their study of Finnish university staff's scholarly communication and how it is influenced by social media.

A recent study (Nicholas et al. 2017) reported that social media platforms are beginning to have an impact, especially in the dissemination arena. One of the most common forms of social media used in academia is microblogging through Twitter (Lupton 2014; Page 2012; 
Rowlands et al. 2011). Twitter is popular for immediate communication, with short messages of up to 140 characters being quick to read and to write (Ebner et al. 2010; Holotescu and Grosseck 2008). With its ability to include links to photos, videos and other online content, it is also a source of news and information. These features mark Twitter's difference with Facebook, which is more popularly used for establishing personal social networks rather than public discourse (Ebner et al. 2010; Ellison, Steinfield, and Lampe 2011). Such abilities make Twitter an ideal platform for scholarly communication in the digital era. However, this is not yet being fully exploited by academics and instances of Twitter use in this aspect have not yet been much studied.

Researchers investigating the use of microblogging by academics suggest that Twitter can benefit academics in various ways: as a platform for scholarly communication, to disseminate research and share information, for establishing contacts and networking, and the development of professional learning networks that enable academics to learn and collaborate with practitioners around the world (Letierce et al. 2010; Lupton,2014; Nicholas et al. 2013; Pearce et al. 2010; Priem and Costello 2010; Rowlands et al. 2011; Veletsianos $2011,2013)$. Twitter can also help to establish scholars' profiles and expertise through giving them a digital presence (Veletsianos et al. 2013; Veletsianos 2011). Meanwhile, a number of studies have reported on students' learning experiences with microblogging and social media (Dunlap and Lowenthal 2009; Greenhow and Robelia 2009; Junco et al. 2011; Rinaldo et al. 2011; Selwyn 2009, 2012). The characteristics of interaction in Twitter align with constructivist and participatory pedagogies.

In his seminal study of postings by 45 active academic tweeters, Veletsianos (2011) identified seven different, but inter-related types of use. The commonest activity was sharing information, resources and media related to the scholar's subject. A related use was to draw attention to scholars' own professional activities and so directly constructing a digital identity. Academics also sought and gave help through Twitter, in conjunction with actively seeking or making connections. Another common use was as in teaching, usually to connect the class to those outside. Veletsianos sees academics' chatter on Twitter about personal interests as significant as a way of "living social public lives". Amplifying other social media presence was the final activity. These activities are related to both professional and personal activities, but the most fundamental impact is on the nature of scholarly communication. In fact, Parra et al. (2015) suggest that Twitter has gained popularity as an essential tool in establishing new links between and among scholarly communities through wider research dissemination.

In general, scholarly communication involves how academics share and publish their research outputs and outcomes to a wider academic community and beyond (Borgman and Furner 2002; Halliday 2001). Graham (2000) characterises it in three main stages: the communication in informal networks like social media, the initial public dissemination in conferences and preprints, and the formal publication of research in scientific journals (Graham 2000). This paper is particularly interested in the first stage of scholarly communication and the role of Twitter at this stage.

The extent to which the possibilities of social media have been realized is still unclear because of a lack of research (Lupton 2014; Veletsianos 2013). Some survey based studies suggest that while Twitter is one of the more popular social media tools in use by academics, it is still used by a minority, and often primarily for personal purposes (Pearson 2013; Tenopir, Volentine and King 2013). Nicholas et al. (2013) suggest that there is a gap between awareness and use, which leads to a host of questions that remain to be investigated. 
Furthermore, the number of in-depth, qualitative studies of these emerging practices is still quite limited. Typically previous studies are of users' experiences were gathered in surveys and have often been about social media use as a whole, not microblogging specifically (Tenopir, Volentine and King 2013; Nicholas et al. 2013; Lupton 2014). Moreover, the insights gained by researchers regarding individuals' practices are reported only at the descriptive and statistical level (Kieslinger and Ebner 2011) that give a broad picture of what is happening rather than detailed explanation of why. The potential of social media such as Twitter has been dubbed as a transformative in political, social and technological lens, but how this relates to scholarly communication in academe brings about potential for research. For instance, although Holmberg and Thelwall (2014) have looked into the scholarly communication activities of academics from different disciplines in their use of Twitter, the very nature of their method meant they were not able to see the details and motives of such use.

\section{OBJECTIVE AND METHOD}

The objective of this research is explore the experiences of academics in using Twitter particularly in how it shapes scholarly communication. Thus the guiding questions for the study were as follows:

(a) What are the different ways academics engage in using Twitter?

(b) How does the use of Twitter change the nature of scholarly communication?

Semi-structured interviews were the main method of data collection in this research. Interview questions asked about the participants' role in general and their use of Twitter, such as when and where they used it, especially on scholarly communication. The study used non-probability or purposeful sampling (Cohen et al. 2007; Creswell 2013) for its sampling strategy, and recruited academics that were actively engaged with Twitter. This sampling strategy is considered to be appropriate for a qualitative study that involves an in-depth interpretation of a complex social phenomenon (Creswell 1998). In this study recruitment occurred at several stages during the course of the research (Miles and Huberman 2010). Four types of sampling conditions were used for the main study: (a) criterion sampling; (b) snowball sampling; (c) recruitment on Twitter; and (d) recruitment emails. Participants were identified through searching Twitter, looking for those following the University and Departmental Twitter accounts, and contacts suggested by initial interviewees. A total of 28 academics from a British University who were active users of Twitter were recruited for the interview, consisting of 12 females and 16 males. There were eleven each from Social Sciences and Arts and Humanities; three from Science, Two from Medicine, dentistry and health; and one from Engineering. The university chosen is strong in both research and teaching and has a global reputation. It is positioned among the top ten of universities in the Russell Group of UK research intensive institutions and in the top 100 in the QS World University Rankings.

There were ten informants between 40-49 years old, the largest age group contributor for the study, followed by eight participants who were aged 30-39 years, seven aged 50 and above and three aged 20-29 years. Interviewees were selected on the basis of their having a Twitter account that was being used for professional purposes; that their account had been registered for at least a year; and that they had to be posting regularly, defined as posting at least one tweet per week. An effort was made to include different disciplines and people at different levels of seniority. All informants were interviewed within the university's 
premises for accessibility and convenience and most interviews were carried out in the participant's office. In total, the interviews ranged in duration from 45 minutes to 2 hours and 10 minutes and was guided by a semi-structured interview protocol. The researcher stopped recruiting participants for interviews when analysis suggested that theoretical saturation had been reached.

Participants were diverse in terms of disciplines, gender, age and levels of seniority. Table 1 gives an overview of the demographics of participants.

Table 1: Profile of Participants*

\begin{tabular}{|c|c|c|c|c|}
\hline Participant & Faculty & Academic status & Gender & Age \\
\hline 1 & Medicine & Professor & Male & $40-49$ \\
\hline 2 & Arts \& Humanities & Lecturer & Female & $30-39$ \\
\hline 3 & Science & Professor & Male & $40-49$ \\
\hline 4 & Arts \& Humanities & Lecturer & Female & $30-39$ \\
\hline 5 & Arts \& Humanities & Lecturer & Female & $30-39$ \\
\hline 6 & Arts \& Humanities & Lecturer & Male & $30-39$ \\
\hline 7 & Social Science & Senior Lecturer & Female & $40-49$ \\
\hline 8 & Social Science & Research Fellow & Male & 30-39 \\
\hline 9 & Social Science & Professor & Male & $40-49$ \\
\hline 10 & Social Science & "University Teacher & Male & $50+$ \\
\hline 11 & Arts \& Humanities & Lecturer & Male & $20-29$ \\
\hline 12 & Engineering & Research Fellow & Female & $40-49$ \\
\hline 13 & Arts \& Humanities & "University Teacher & Male & $20-29$ \\
\hline 14 & Arts \& Humanities & Senior Lecturer & Female & $40-49$ \\
\hline 15 & Social Science & Professor & Female & $50+$ \\
\hline 16 & Arts \& Humanities & Lecturer & Female & $20-29$ \\
\hline 17 & Social Science & Professor & $\begin{array}{l}\text { Female } \\
\end{array}$ & $50+$ \\
\hline 18 & Arts \& Humanities & Research Fellow & Male & 30-39 \\
\hline 19 & $\begin{array}{l}\text { Social Science } \\
\end{array}$ & Senior Lecturer & Male & $30-39$ \\
\hline 20 & Science & Professor & Male & $40-49$ \\
\hline 21 & Science & Professor & Male & $50+$ \\
\hline 22 & Arts \& Humanities & Senior Lecturer & Male & $40-49$ \\
\hline 23 & Social Science & University Teacher & Male & $50+$ \\
\hline 24 & Social Science & Lecturer & Female & 30-39 \\
\hline 25 & Medicine & Lecturer & $\begin{array}{l}\text { Female } \\
\end{array}$ & $40-49$ \\
\hline 26 & Arts \& Humanities & Professor & Female & $50+$ \\
\hline 27 & Social Science & Professor & Male & $50+$ \\
\hline 28 & Social Science & Senior Lecturer & Male & $40-49$ \\
\hline
\end{tabular}

*M - Medicine; A\& H - Arts \& Humanities; S - Science; SS - Social Science

*P - Professor; L - Lecturer; SL - Senior Lecturer; RF - Research Fellow; UT - University Teacher

To ensure the research was of a good quality, specific strategies were applied including credibility, transferability, confirmability and dependability to ensure consistency and strength of this qualitative research following Guba and Lincoln (1985), Creswell (1998) Creswell and Miller (2000). The following key approaches were used to enhance the research rigor and trustworthiness:

(a) Audit trail: The audit trail is important in establishing the credibility of a piece of research. In this study, systematic organisation of every document used for the purpose of research (e.g. ethical approval, information consent, participant 
information sheet, interviews questionnaires, interview transcripts, reflexive notes, codes and documentation of theme development) was maintained to form an audit trail. This was done to ensure transparency of the research process, especially when it will be reported to other people within and outside the university.

(b) Member checking: the researcher constantly sought clarification through asking the participants about concepts that developed during interviews and to explain their reasons for such views, in order to develop a formative understanding of contextual meanings (Shenton 2004).

(c) Peer review: This form of quality control was through peer and colleagues' reviews of presentations at conferences of the research and publications through double blind peer review.

(d) Thick description of the phenomenon under study: This study sought credibility through its rich descriptions that provide detailed accounts of the research context which gives the reader a deeper sense of the phenomenon.

(e) Examination of previous research findings: Silverman (2006) considered the key criterion of assessing the qualitative study is the ability to discuss the results and compare and evaluate them in relation to prior studies in the field.

A thematic approach was taken to data analysis (Braun and Clarke 2006). Thematic analysis is a technique commonly used in interpretive studies and has been claimed to be a "foundational method for qualitative analysis" (Boyatzis 1998; Braun and Clarke 2006). This form of analysis helps organize the detail of a rich dataset, highlighting what is common and where there are differences among the interviewees, and generating themes that describe the meaning of the data. Braun and Clarke's (2006) thematic analysis strategy consists of a six-step process: (a) data familiarization, (b) generation of initial codes, (c) searching for themes, (d) reviewing the themes, (e) naming themes, and (f) reporting findings. The approach here was a mixed approach with some codes derived from the literature and some grounded in the data. NVivo, the software for qualitative data analysis, was used to support the analysis process.

This study has developed a framework for understanding the academics' use and adoption of Twitter in higher education. It offers significant implications for experiences in similar contexts. The university and the academics could be considered to be fairly typical and the results might well be mirrored within similar research institutions (e.g. Russell Group universities) that have a similar environment. Further, a wide range of interviewees (i.e. of different gender, age, research disciplines, academic level of seniority) were involved in this study representing the typical range of experiences in academia.

\section{RESULTS}

\section{Academics' Use of Twitter}

The thematic analysis found five key themes relating to academic practice. The uses are as follows: creating a community of interest; keeping informed; creating digital identity; teaching; and regulating micro-breaks.

\section{(a) Creating a Community of Interest}

Not surprisingly, the primary reason why academics were attracted to Twitter was its promise as a means of communication. More than a purely social platform, Twitter was found to be a space for academic discussion, dissemination of research and social interaction, through which interviewees were able to share ideas and raise issues. This is 
interesting since this is a form of scholarly communication, but it is informal. Stylistically, Twitter's informality in relation to scholarly communication was felt to promote an accessible communication. As mentioned by one respondent:

"[Twitter is a] good way of informalizing academic discourse, which can be alienating and [...] overly formal [...] Twitter can humanise what can be a very robotic process [...] academic discourse can sometimes be [...] purposely dense, and because [of] the concise nature of Twitter and because of its instantaneous nature I think it can be a necessarily loosening of that, which is potentially quite progressive." [11L-A\&H]

Central to Twitter's value to the interviewees was that it was able to maintain a supportive and inspiring community of interest.

"I had a very supportive kind of community of shared interests and I still follow mostly probably historians and journalists, writers, things like that, so it's a community of likeminded people." [4L-A\&H]

"I had very supportive, interesting interactions with all of these nice people who then introduced me to other people and it made it feel like an actual community of people rather than just [...] somewhere where people broadcast." [6L-A\&H]

"We had this conversation and... I think it went on for about half an hour or so... [...] It was really cool! By the time I got to work I was all enthusiastic about research and ideas and thinking about things and in fact it inspired me to write a book about the experiences and ideas that came out of these discussions." [24L-SS]

The existence of a Twitter community around their topic enabled them to establish their own presence. They become "visible to the community around what you study." [16L-A\&H]

As part of scholarly communication, Twitter engagement was seen to be an opportunity to disseminate research outputs. This is evidenced by times when the academics "...tweet when I have a paper published..." [1P-M] or when "... a new journal article [is] out: I'll tweet a link to it!" [8RF-SS]

This activity was quite purposive, but in keeping with the community feel they would also promote other people's work and general relevant news. In a way, Twitter was a means of "signaling stuff" or likened to a notice board.

"So, I use it to disseminate not only my own research but new stories or other people's research in my area. But I also I think it is a fantastic learning resource for students' cause other people are doing the same academic, professional work in similar areas and I think you can learn about." [25L-M]

Accordingly, building a network of contacts was seen to be made easier by Twitter. This was especially important to early career researchers among interviewees. For instance, one could establish contacts prior to a conference to avoid the experience of arriving at the event not knowing anyone. Having encountered them on Twitter, it was easier to talk to people if they met in real life.

"You start to make connections with some of their colleagues you haven't met, and so I have made acquaintances that way before and there have been occasions where I've met people in the School and had to say, 'It's good to see you. We've talked on Twitter lots of times before but it's the first time l've actually met you." [23UT-SS]

The network was able to create opportunities to participate in scholarly activities, which the participants thought would not have otherwise arisen. They did have a sense that hierarchical distance between academics had been reduced when they engaged in Twitter. 
As a result, collaborative and interdisciplinary opportunities widened for most participants. This was of particular importance in the minds of early career researchers since they are expected to widen their network and collaborate with academics.

Part of the appeal was the breadth of the community. It might include a handful of fellow scholars interested in a narrow topic; but it was likely to include journalists, funders and wider publics.

"What Twitter does is connect me to [...] the 15-other people in the world who are interested in the same thing. There's no way that I could come to work and meet two other people who read the article and have ideas about it, and what Twitter does it just make the world smaller." [24L-SS]

A key aspect of Twitter was its ability to reach wider publics. The value of this reflected the growing imperative for research to reach beyond academia for wider impact. In fact, the respondents even mentioned that the community could include funders, which naturally is important for researchers.

Accordingly, it helped to create and document wider engagements with research, where impact was hard to measure. This advantage was seen to cut across disciplines.

"So, it's easy in Engineering because, you know, they build buildings. They make sure buildings stay up and bridges stay up etc. How about poetry? [...] Why is poetry useful? Well, it's because people like it, right, and it says something to them about their lives, but we must communicate with the public or else it's not useful." [18FR-A\&H]

"So if [...] I want to be able to demonstrate dissemination then I would probably put it out though Hootsuite so I then have the report saying this is how many people, this is the proportion from this country, from other countries.[...] In Arts and Humanities it's often less straightforward to demonstrate the impact of research because you're looking at something that's slightly less easy to pin down, so I think showing the public range of people, showing the numbers of people who might be looking at tweets, looking at websites and buying books and so on." [5L-A\&H]

"[...] it generally demonstrates a kind of broad dissemination of research and work connected to your research beyond just the university academic environment. It's really important..." [6L-A\&H]

Engagement with communities was partly through the community of interest as a whole, but Twitter did enable specific activities that reached out to circles beyond academia:

"One thing I did which is quite interesting was I took part in a Twitter interview with the group [of] kids from a school in London called [school name]. And this kind of, there must have been 20 tweets that day them asking me questions, me answering and the whole thing was done on Twitter." [3P-S]

Such engagement might extend to wider civic engagement and involvement in local affairs. Several participants reflected on commenting on local current affairs, such as complaining about local services.

Twitter's ability to simultaneously talk to multiple audiences was a recurring sub-theme in interviewees' comments.

"I can sit on this office and not leave for the whole day, because I have a lot to do; whereas with Twitter I can reach 800 people around the world in 30 seconds. I can't do that with email, I can't do that in a public lecture, I can't do that in the paper I have written, so it's an immediate way of touching lots of people, and I think, as an academic, we have a duty to have a dialogue and connect with people, and it's just another tool to do that." [1P-M] 
As well as helping to create a community of interest, Twitter could also support specific collaborations, though this was mentioned less than creating a broad community of interest. For example, it was seen as helping maintain broad awareness among participants in a distributed project, or it could support direct collaboration on a joint project:

"I first used Twitter in a very strange way, when it first appeared, to try to write a book with somebody. The idea was that we were going to tweet things to each other and slowly write a book, so I had a Twitter account with only one follower and that was completely private." [9P-SS]

\section{(b) Keeping Informed}

A natural corollary of participating in such a community around their field of interest, was that Twitter was seen as a channel through which they themselves kept informed and also a means of actively learning. In addition to networking and collaboration, participants in the study were also engaged in accessing or seeking information. This is based on their notion that it is a "...a specialized news channel..." [21P-S] or a "...almost like a custom-made magazine..." [27P-SS] The information accessed by the academics depended on the people that they 'follow' or those who 'follow' them.

"Twitter is beneficial because I use it as a way of collecting information that I need...I do follow people who are going to provide information for me." [1P-M]

It was seen as a way to keep up with current news and other personal interests. It minimized time and effort in information seeking, often being the first-place news was seen. It also fitted into routines of reading journals. It was felt to broaden people's reading, and encounter a broader range of views.

\section{(c) Creating a Digital Identity}

Over time, participants had created a relatively pre-meditated digital identity on Twitter. The main common features of this identity were that they wished to present themselves as interesting, a valuable information source and as someone engaged with wider publics. Such identity presentation is still related to how they want to be seen as academics engaged in scholarly activities rather than mere social media user, and "...someone who provides useful information to other people" [12FR-E]. They sought to balance being professional and humanizing themselves.

"Establishing yourself as a person who tweets interesting things, means probably that people are more likely than to engage with your books or your articles or your blog posts and that sort of thing, so it does help to increase the public reach of what I'm writing." [4L$\mathrm{A} \& \mathrm{H}]$

Their Twitter activity was partly to self-consciously promote themselves, in a competitive environment.

"My Twitter account is about me as a historian and author having a kind of public profile as me, sort of marketing of me. [...] It is about building a kind of identity for you as a named author so that people will be interested in buying your next book." [5L-A\&H]

Twitter was used to amplify their other social media presence. More than half of interviewees mentioned using Twitter as a way of "directing people to my blog" or "taking them to my website". Still, this is related to the scholarly communication and how they create and negotiate information sharing. Yet in keeping with the community, they also promoted colleagues, news related to their area and the university. 


\section{(d) Teaching}

Being in the academe, the respondents of this study also had responsibilities as teachers in and out of the classroom. This use was linked to its use within scholarship. Creating a community of interest and projecting a digital identity, with a human side, encompassed drawing in current students and alumni to the community around their research interests. The desire to humanize themselves in their digital identity extended specifically to students. This is done by "...build[ing] up like a kind of rapport with students so they can get to see you a little bit as a real person..." [6L-A\&H]

Twitter was also used directly in teaching. This was primarily through posting relevant news with a class hashtag and continuing classroom discussion.

"For instance, if I was reading the Guardian and there was an article which I thought, 'Oh, that would be really interesting to my students on that module', I could tweet, put a hashtag that was the module code and went, you know, "[course name] students, you'll love this Guardian article" and tweeted it... I think it's a great way of sharing. [...] Twitter [...] has great potential to capture those fleeting moments of relevance to a module that happens outside the classroom." [5L-A\&H]

This engagement allows the academic as a teacher to communicate more frequently and longer than the normal class hours that they usually allot to students. This extended the interaction between staff and students, in a way that made for a more engaging form of what one interviewee dubbed "conversational learning".

"As I say, it's conversational. It's conversational learning and... it takes you beyond the lecture theatre and it's actually a more efficient use of time, I think, rather than trying to make all these points when we're all together in the room. Everybody gets bored. You know, you can do them in little bites over a longer period." [10UT-SS]

Connected to this Twitter was a means to answer questions and offer help and support. It was more efficient in that an email would just be one-to-one, but a tweet could be one-tomany.

"Students just asking general questions and struggling with things, so having concerns about things that they tweet about and it means that you can help them and that you can do that in a way that you couldn't with email because they wouldn't email you to ask you about something but if they just post it generally and then not necessarily directing it to any one particular person then it means that you can help and support them in a kinder sort of subtle way." [13UT-A\&H]

In some subjects Twitter use was a professional practice that needed to be learned, so it naturally was a tool to teach directly in class and off the classroom.

\section{(e) Micro-breaks}

Interestingly, participants mentioned about how they used Twitter as a past time, on top of the scholarly activities they were generally engaged with. According to them, Twitter filled gaps and down time, such as the journey to and from work.

"Part of the reason may be that I started tweeting was because I commute... five days a week... and it is a train journey for about an hour so what tends to happen is I read all my Twitter feeds and then I read the news and then I respond to my [feeds] on Twitter and probably post about the news. And that is kind of my hour's journey into work." [16L-A\&H]

"It's almost like twiddling your thumbs." [19SL-SS]

"I sometimes [browse Twitter] when I am in the toilet, or in the bath or waiting for a bus." [1P-M] 
But it could have a more positive value than simply filling down time. Twitter was a way to take a brief break from boring or taxing work, as they considered it "as a release". It was a break to more routine or tiresome tasks, particularly email. The researchers propose the term micro-break to describe this use.

"When I have a kind of admin-type day, if I'm doing lots of bits, small things like emails, then I might well tweet in between, comment on things, retweet and so forth [...] it's sort of when it fits into what I'm doing with other things." [5L-A\&H]

Working on something that required great concentration benefited from the small breaks offered by Twitter too.

"I can be scrolling through the Twitter feed but it's just giving me a quick break from that sentence that I'm trying to write, that para[graph], that idea I'm trying to grapple with and while I'm having that break." [2L-A\&H]

Participants did see some risks in Twitter as a micro-break, as it could lead to procrastination or shallow concentration, contradicting scholarly academic activities.

\section{DISCUSSION}

The academics in this study were Twitter enthusiasts who adopted the tool in various ways, especially for scholarly communication and for micro-breaks. This involved monitoring and tweeting frequently for research, for teaching and for personal interest. Twitter helped create and maintain communities of interest, encompassing fellow researchers, funders, the media, students and the public. Much activity within the community revolved around disseminating research outputs. Interviewees promoted their own research, but also the work of colleagues and developments relating to their field more generally. Scholars selfconsciously created a carefully crafted digital identity. Twitter was often used in conjunction with other social media, to amplify the message within the wider context of scholarly communication. It was also used to document engagements and the impact of dissemination. These findings are very much consistent with uses Veletsianos (2011) identified and with Lupton's (2014) findings for social media as a whole.

Twitter was a valued source of information, both academic and relating to general news and personal interest. Such activity was mostly in the context of content creation, usage and sharing of scholarly information. This confirms what Priem and Costello (2010) have argued about the potential of Twitter in measuring scholarly impact through communicating scientific articles to a wide audience. While various researchers have claimed that Twitter is often used as a backchannel during conferences (Holmberg and Thelwall 2014), the findings of this research suggest that Twitter is more than just that and not primarily based on time limited events (Veletsianos and Kimmons 2016). It actually has a role and impact in communicating and use of scholarly information. This practice links to a concern for presenting a digital public image that depicts the subject as an interesting, professional and personable character. Participants were keen not to be seen as old-fashioned academics in an ivory tower, rather through Twitter they wanted to be seen as interesting, open to wider publics and human. Furthermore, Twitter supports academics in their professional growth through the professional learning networks opportunities such as collaborations, sharing research ideas, teaching perspectives, offer and received feedback and learning about new technological tools from community of interest (Trust et al. 2017). 
Twitter has become a very popular social media platform. For some academics, like the interviewees in this study, it was genuinely transforming their communication: achieving the goals of "openness, collaboration, networking, engagement and transparency" defined by Weller (2011) as the attributes of the digital scholar. They worked more collaboratively, and not just with fellow academics, but also professionals and they connected more locally and globally. Their visibility in their field was greater. They did more high-quality research, disseminated the results more widely and had more evidence of impact. For this reason, Twitter seems to be an engaging activity among these academics, which is related to the point of Holmberg and Thelwall (2014) that some disciplines are still apprehensive of the purpose and use of Twitter in their academic activities. On the contrary, this was not the case among Italian academics since there were more of them who use ResearchGate and LinkedIn than Twitter and other social media (Manca and Ranieri 2017). Moreover, Twitter was most valuable to early career researchers to create visibility and a supportive network. Such motivations, including maintaining and widening networks were also mentioned by Donelan (2016) when he looked into the professional development and networking opportunities in academia.

However, participants also expressed a range of concerns around reputational risk, distraction, information quality and privacy. Interviewees were enthusiastic and evangelistic about using Twitter. Yet a small minority of academic staff in this institution were actively posting on Twitter, a pattern also seen by Gu and Widen-Wuff (2010). A number of the ways interviewees had adopted and used Twitter, suggest reasons why it was only a minority interest at this institution. Although technology enthusiasts and early adopters, interviewees had taken a long time to work out how to use Twitter, suggesting that it was not easy to fit it in with other practices and there was also a barrier of initial skepticism. Also, interviewees were commonly using Twitter to amplify other social media use. So those without a web site or blog would find less use for it. This is related to the discussion of Mahrt, Weller and Peters (2014) on the Twitter uptake of academics, which mainly included tweeting during conferences and posting URLs linked to their scholarly activities or publications. Use of Twitter was primarily being used to create a profile in a research community. Those with an existing strong community profile or lacking a strong research interest which they wanted to promote would not need it. Twitter use was particularly popular among those who wanted to prove impact, where it was otherwise hard to demonstrate.

Furthermore the evidence suggested that realizing the value of Twitter took a considerable investment of time and effort. Users were typically people who self-identified as technology enthusiasts and early adopters, and coupled their use of Twitter with other social media. This is a minority profile. The informality of Twitter improved the freedom of academic discourse, but there were perceived to be considerable reputational risks around not adopting a positive, professional tone. Again, care had to be taken in maintaining professional relations with students on Twitter. Using Twitter was often time consuming and distractive; it could create information overload. So, use was surrounded by a number of concerns that had to be carefully managed, as Lupton (2014) has suggested. Reflecting on these factors gives us a more balanced perspective on Twitter use, than simply reiterating the discourse around digital scholarship in an unqualified way.

\section{CONCLUSION}

This study contributes to addressing the call from Veletsianos and Kimmons (2016) for more interpretive and qualitative studies of the scholarly use of Twitter. It has presented the 
results of a study of Twitter use in a British University, based on in-depth interviews of 28 academics. It was found that Twitter was valued for its ability to support a broad community of interest around interviewees' subject area. This also meant it was a valued information source, especially in the context of creation, usage and sharing of scholarly information. For the participants something of the concept of digital scholarship (Weller 2011) or networked participatory scholarship (Veletsianos and Kimmons 2012) was being realized. The paper also proposes the concept of micro-break, to describe how Twitter was used as a short, but productive interruption to boring or demanding tasks. Finally, the paper also makes a contribution by offering insights into why Twitter use, despite these advantages, remains a minority practice: such as the strong link to amplifying other social media, the time it demands to use it and perceived reputational risks.

While this was a study only of academics in one institution, the results are largely consistent with other findings in the literature, suggesting that the results are not unrepresentative. Nevertheless, the current findings do prompt directions for future research. On the one hand, more detailed studies of practices of Twitter use could bring together a comparison of self-reported explanations of activity from qualitative data and quantitative evidence about the time, location and content of Twitter postings. Equally, on the other hand, survey based studies exploring the low adoption of Twitter in institutions as a whole would be of value.

In terms of practical implications, for those seeking to promote the use of Twitter in HE, two areas stand out as where activity might focus: Firstly, reducing the effort of gaining familiarity with Twitter and, secondly, reducing the sense of risk that surrounds Twitter use. Many institutions already have social media use guidelines. While technically not hard to use, know how about using it effectively is of value, so training in this would reduce the barriers to Twitter use. Another useful strategy would be promoting awareness through identifying role models, such as the people in the interviewees in this study, who have direct experience of the benefits of Twitter use. However, it seems that Twitter use involves a commitment to openly sharing many aspects of professional work, that is a fundamental cultural change. It is hard to see how training by itself, would convert people to its use, unless a lot of other pre-conditions exist.

\section{ACKNOWLEDGEMENT}

This research received no specific grant from any funding agency in the public, commercial, or not-for profit sectors. There are no conflicts of interest involving either of the authors of this paper.

\section{REFERENCES}

Alderton, E., Brunsell, E. and Bariexca, D. 2011. The end of isolation. MERLOT Journal of Online Learning and Teaching, Vol.7, no.3: 354-365.

Braun, V. and Clarke, V. 2006. Using thematic analysis in psychology. Qualitative Research in Psychology, Vol.3, no.2: 77-101. Available at: http://dx.doi.org/10.1191/ 1478088706qp063oa.

Borgman, C.L., and Furner, J. 2002. Scholarly communication and bibliometrics. Annual Review of Information Science and Technology, Vol.36, no.1: 2-72. 
Boyatzis, R. 1998. Transforming qualitative information: Thematic analysis and code development. Thousand Oaks, CA: Sage Publications.

Donelan, H. 2016. Social media for professional development and networking opportunities in academia. Journal of Further and Higher Education, Vol.40, no.5: 706-729.

Dunlap, J. C. and Lowenthal, P. R. 2009. Tweeting the night away: Using Twitter to enhance social presence. Journal of Information Systems, Vol.20, no.2: 129-135.

Ebner, M., Lienhardt, C., Rohs, M. and Meyer, I. 2010. Microblogs in higher education - A chance to facilitate informal and process-oriented learning? Computers and Education, Vol. 55, no.1: 92-100. http://doi.org/10.1016/j.compedu.2009.12.006.

Ellison, N. B., Steinfield, C. and Lampe, C. 2011. Connection strategies: Social capital implications of Facebook-enabled communication practices. New Media \& Society, Vol. 13, no.6: 873-892. Available at: http://doi.org/10.1177/1461444810385389.

Foroughi, A. 2011. A research framework for evaluating the effectiveness of implementations of social media in higher education. Online Journal for Workforce Education and Development, Vol. 5, no.1: 5.

Graham, T.W. 2000. Scholarly communication. Serials, Vol.13, no.1: 3-11.

Greenhow, C. and Robelia, B. 2009. Informal learning and identity formation in online social networks. Learning, Media and Technology, Vol. 34, no.2: 119-140. Available at: http://doi.org/10.1080/17439880902923580.

Greenhow, C. and Gleason, B. 2014. Social scholarship: Reconsidering scholarly practices in the age of social media. British Journal of Educational Technology, Vol.45: 392-402. Available at: http://doi.org/10.1111/bjet.12150

Gu., F., and Widen-Wulff, G. 2010. Scholarly communication and possible changes in the context of social media: A Finnish case study. The Electronic Library, Vol.29, no.6: 726776.

Guba, E., Lincoln, Y., Denzin, N., and Lincoln, Y. 1998. The landscape of qualitative research: Theories and issues. London: Sage Publications.

Halliday, L. 2001. Scholarly communication, scholarly publication and the status of emerging formats. Information Research, Vol. 6, no.4. Available at: http://www.informationr.net/ir/6-4/paper111.html.

Holmberg, K., and Thelwall, M. 2014. Disciplinary differences in Twitter scholarly communication. Scientometrics, Vol. 101, no. 2: 1027-1042. Available at: https://link.springer.com/article/10.1007/s11192-014-1229-3.

Holotescu, C. and Grosseck, G. 2008. Using microblogging in education. Case Study: Cirip.ro. Procedia - Social and Behavioral Sciences, Vol.1, no.1: 495-501. Available at: doi:10.1016/j.sbspro.2009.01.090.

Junco, R., Heiberger, G. and Loken, E. 2011. The effect of Twitter on college student engagement and grades. Journal of Computer Assisted Learning, Vol.27, no.2: 119-132. Available at: http://doi.org/10.1111/j.1365-2729.2010.00387.x.

Kieslinger, B. and Ebner, M. 2011. A Qualitative approach towards discovering microblogging practices of scientists. Proceedings of the Interactive Collaborative Learning (ICL) 2011 Conference, Pieštany, Slovakia: 51-57. Available at: doi: 10.1109/ICL.2011.6059547.

Kirkup, G. 2010. Academic blogging: academic practice and academic identity. London Review of Education, Vol.8, no.1: 75-84. Available at: http://doi.org/10.1080/14748460903557803.

Letierce, J., Passant, A., Decker, S. and Breslin, J. G. 2010. Understanding how Twitter is used to spread scientific messages. Paper presented at the Web Science Conference, Raleigh, NC, USA. April 26-27, 2010. Available at: http://journal.webscience.org/314/.

Lupton, D. 2014. 'Feeling better connected': Academics' use of social media. Canberra: News $\&$ Media Research Center, University of Canberra. 
Mahrt, M., Weller, K., and Peters, I. 2014. Twitter in scholarly communication. In Twitter and Society, K. Weller, A. Bruns, J. Burgess, M. Mahrt, and C. Puschmann. (Eds.). NY: Peter Lang Publishing, Inc.: 399-410.

Manca, S., and Ranieri, M. 2017. Networked scholarship and motivations for social media use in scholarly communication. International Review of Research in Open and Distributed Learning, Vol.18 no.2: 123-138.

Miles, M. and Huberman, A. 1994. Qualitative data analysis: An expanded sourcebook. Thousand Oaks: Sage.

Nicholas, D., Watkinson, A., Boukacem-Zeghmouri, C., Rodríguez-Bravo, B., Xu, J., Abrizah, A., Świgoń, M. and Herman, E. 2017, Early career researchers: Scholarly behaviour and the prospect of change. Learned Publishing, 30: 157-166. Available at: doi:10.1002/leap.1098.

Nicholas, D., Watkinson, A. and Christensen, R. 2013. Trust and authority in scholarly communications in the light of the digital transition: Final Report, NY: Alfred P. Sloan Foundation. Available at: http://ciber-research.eu/download/20140115Trust_Final_Report.pdf.

Nicholas, D. and Rowlands, I. 2011. Social media use in the research workflow. Information Services and Use, Vol.31, no.1-2: 61-83. Available at: http://doi.org/10.3233/ISU-20110623.

Page, R. 2012. The linguistics of self-branding and micro-celebrity in Twitter: The role of hashtags. Discourse \& Communication, Vol.6, no.2: 181-121. Available at: http://doi.org/10.1177/1750481312437441.

Pepe, A. and Mayernik, M. S. 2011. The use of microblogging for field-based scientific research. Proceedings of the Annual Hawaii International Conference on System Sciences: 1666-1675. Available at: http://doi.org/10.1109/HICSS.2012.589

Pearce, N., Weller, M., Scanlon, E. and Kinsley, S. 2010. Digital scholarship considered: How new technologies could transform academic work. E in Education, Vol.16, no.1: 33-44.

Pearson, E. 2009. All the World Wide Web's a stage: The performance of identity in online social networks. First Monday, Vol. 14, no. 2: Available at: http://firstmonday.org/htbin/cgiwrap/bin/ojs/index.php/fm/article/viewArticle/2162.

Priem, J. and Costello, K. L. 2010. How and why scholars cite on Twitter. Proceedings of the American Society for Information Science and Technology Annual Meeting, Vol.47, no.1: 1-4. Available at: doi: 10.1002/meet.14504701201.

Reuben, R. 2008. The use of social media in higher education for marketing and communications: A guide for professionals in higher education. Available at: http://www.fullerton.edu/technologyservices/_resources/pdfs/social-media-in-highereducation.pdf.

Rinaldo, S.B., Laverie, D.A. and Tapp, S. 2011. Learning by tweeting: Using Twitter as a pedagogical tool. Journal of Marketing Education, Vol.33: 193-203. Available at: http://doi.org/10.1177/0273475311410852.

Rowlands, I., Nicholas, D., Russell, B., Canty, N. and Watkinson, A. 2011. Social media use in the research workflow. Learned Publishing, Vol.24, no.3: 183-195. Available at: http://doi.org/10.1087/20110306.

Selwyn, N. 2007. The use of computer technology in university teaching and learning: A critical perspective. Journal of Computer Assisted Learning, Vol.23: 83-94. Available at: http://doi.org/10.1111/j.1365-2729.2006.00204.x.

Selwyn, N. 2009. The digital native: Myth and reality. Aslib Proceedings, Vol.61, no.4: 364379. http://doi.org/10.1108/00012530910973776.

Selwyn, N. 2012. Social media in higher education. In A. Gladman (Ed.), The Europa world of learning: 1-9. London, UK: Routledge. 
Silverman, D. 2006. Interpreting qualitative data: Methods for analyzing talk, text, and interaction. Thousand Oaks, CA: SAGE Publications.

Shenton, A. K. 2004. Strategies for ensuring trustworthiness in qualitative research projects. Education Information, Vol.22, :63-75. Available at: http://www.crec.co.uk/docs/Trustworthypaper.pdf.

Tenopir, C., Volentine, R. and King, D.W. 2013. Social media and scholarly reading. Online Information Review, Vol.37, no.2: 193-216. Available at: http://doi.org/10.1108/OIR04-2012-0062.

Trust, T., Krutka, D. G. and Carpenter, J. P. 2016. "Together we are better": Professional learning networks for teachers. Computers \& Education, Vol.102: 15-34.

Veletsianos, G. 2011. Higher education scholars' participation and practices on Twitter. Journal of Computer Assisted Learning, Vol.28, no.4: 336-349. Available at: doi: 10.1111/j.1365-2729.2011.00449.x.

Veletsianos, G. and Kimmons, R. 2012a. Assumptions and challenges of open scholarship. International Review of Research in Open and Distance Learning, Vol.13:166-189.

Veletsianos, G. and Kimmons, R. 2012b. Networked Participatory Scholarship: Emergent techno-cultural pressures toward open and digital scholarship in online networks. Computers and Education, Vol.58, 2: 766-774. Available at: http://doi.org/10.1016/j.compedu.2011.10.001.

Veletsianos, G. and Kimmons, R. 2012. Scholars and faculty members' lived experiences in online social networks. The Internet and Higher Education, Vol.16, :43-50. Available at: http://doi.org/10.1016/j.iheduc.2012.01.004.

Veletsianos, G. 2013. Open practices and identity: Evidence from researchers and educators' social media participation. British Journal of Educational Technology, Vol.44, no.4: 639651. Available at: http://doi.org/10.1111/bjet.12052.

Veletsianos, G., and Kimmons, R. 2016. Scholars in an increasingly open and digital world: How do education professors and students use Twitter? Internet and Higher Education, Vol.30:1-10. Available at: http://dx.doi.org/10.1016/j.iheduc.2016.02.002.

Veletsianos, G., Kimmons, R. and French, K. D. 2013. Instructor experiences with a social networking site in a higher education setting: Expectations, frustrations, appropriation, and compartmentalization. Educational Technology Research and Development, Vol. 61 no.2: 255-278. Available at: http://doi.org/10.1007/s11423-012-9284-.z.

Weller, M. 2011. The digital scholar: How technology is transforming scholarly practice. London: Bloomsbury.

Wright, N. 2010. Twittering in teacher education: Reflecting on practicum experiences. Open Learning: The Journal of Open and Distance Learning, Vol.25, no.3: 259-265. Available at: doi:10.1080/02680513.2010.512102. 